\title{
Astragaloside IV facilitates glucose transport in C2C12 myotubes through the IRS1/AKT pathway and suppresses the palmitate-induced activation of the IKK/IкB $\alpha$ pathway
}

\author{
RONGFENG ZHU, JIANJUN ZHENG, LIZHEN CHEN, BIN GU and SHENGLI HUANG
}

Department of Internal Medicine, The 95th Hospital of Chinese People's Liberation Army, Putian, Fujian 351100, P.R. China

Received December 17, 2015; Accepted March 29, 2016

DOI: $10.3892 / \mathrm{ijmm} .2016 .2555$

\begin{abstract}
Astragaloside IV is a monomer isolated from Astragalus membranaceus (Fisch.) Bunge, which is one of the most widely used plant-derived drugs in traditional Chinese medicine for diabetes therapy. In the present study, we aimed to examine the effects of astragaloside IV on glucose in $\mathrm{C} 2 \mathrm{C} 12$ myotubes and the underlying molecular mechanisms responsible for these effects. Four-day differentiated $\mathrm{C} 2 \mathrm{C} 12$ myotubes were exposed to palmitate for $16 \mathrm{~h}$ in order to establish a model of insulin resistance and ${ }^{3} \mathrm{H}$ glucose uptake, using 2-Deoxy-D-[1,2- $\left.{ }^{3} \mathrm{H}(\mathrm{N})\right]$-glucose (radiolabeled 2-DG), was detected. Astragaloside IV was added $2 \mathrm{~h}$ prior to palmitate exposure. The translocation of glucose transporter 4 (GLUT4) was evaluated by subcellular fractionation, and the expression of insulin signaling molecules such as insulin receptor $\beta$ (IR $\beta$ ), insulin receptor substrate (IRS) 1 /protein kinase B (AKT) and inhibitory $\kappa \mathrm{B}$ kinase $(\mathrm{IKK}) /$ inhibitor- $\kappa \mathrm{B} \alpha(\mathrm{I} \kappa \mathrm{B} \alpha)$, which are associated with insulin signal transduction, were assessed in the basal or the insulin-stimulated state using western blot analysis or RT-PCR. We also examined the mRNA expression of monocyte chemotactic protein 1 (MCP-1), interleukin 6 (IL-6), tumor necrosis factor $\alpha(\mathrm{TNF} \alpha)$ and Toll-like receptor 4 (TLR4). Taken together, these findings demonstrated that astragaloside IV facilitates glucose transport in C2C12 myotubes through a mechanism involving the IRS1/ AKT pathway, and suppresses the palmitate-induced activation of the $\mathrm{IKK} / \mathrm{I} \kappa \mathrm{B} \alpha$ pathway.
\end{abstract}

Correspondence to: Professor Shengli Huang, Department of Internal Medicine, The 95th Hospital of Chinese People's Liberation Army, 486 Donglan Road, Putian, Fujian 351100, P.R. China E-mail: 123357213@qq.com

Abbreviations: AS, astragaloside IV; PA, palmitate; IRS1, insulin receptor substrate 1; AKT, protein kinase B; GLUT4, glucose transporter 4; IR $\beta$, insulin receptor $\beta$; MCP-1, monocyte chemotactic protein 1; TLR4, Toll-like receptor 4; IL-6, interleukin-6; TNF $\alpha$, tumor necrosis factor $\alpha$; I $\mathrm{B} \alpha$, inhibitor $\kappa \mathrm{B} \alpha$; IKK, inhibitory $\kappa \mathrm{B}$ kinase

Key words: astragaloside IV, $\mathrm{C} 2 \mathrm{C} 12$ myotube, palmitate, insulin resistance, glucose uptake

\section{Introduction}

Skeletal muscle accounts for $40 \%$ of body weight in humans, and $75 \%$ of infused glucose is cleared by skeletal muscle $(1,2)$; thus, skeletal muscle serves as the major site of insulin-dependent glucose uptake. Due to the key role played by skeletal muscle in glucose homeostasis, deleterious factors which provoke reductions in glucose uptake by skeletal muscle, described as skeletal muscle insulin resistance, may lead to decreases in the disposal rate of serum glucose (3).

The etiology of impaired insulin signaling in obese individuals is multifactorial and appears to be associated with at least two major events: a state of chronic, low-grade inflammation and the accumulation of intramyocellular lipids (4). Under physiological conditions, serum free fatty acids (FFAs) are an important fuel source for skeletal muscle, and $98-99 \%$ of FFAs bind to bovine serum albumin (5). Therefore, physiological concentrations of FFAs are in the $\mu \mathrm{mol} / 1$ range (5). Constantly elevated serum levels of FFAs result in the transportation of FFAs into skeletal muscle cells, and subsequently stored as triglyceride. Whenever the accumulation of triglycerides and/or hydrolysis of triglycerides exceeds the oxidation capacity, incomplete lipid metabolic products, such as acyl-CoA, diacylglycerol and ceramide, are generated. These products inhibit the activation of critical molecules involved in insulin signaling, such as protein kinase B (AKT) and insulin receptor substrate (IRS)1 (6), reduce insulin sensitivity, leading to insulin resistance in skeletal muscle. Previous studies of muscle from diabetic rodents and human subjects demonstrated that pharmacological agents, such as 5-aminoimidazole-4-carboxamide riboside (AICAR) (7), metformin (8), thiazolidinediones (TZD) $(9,10)$ and ciliary neurotrophic factor (11), increase muscle glucose uptake, and that this response is maintained.

Astragaloside IV, a 3-O- $\beta$-D-xylopyranosyl-6-O- $\beta$-Dglucopyranosylcycloastragenol purified from Astragalus membranaceus (Fisch.) Bunge, is one of the most widely used plant-derived drugs in traditional Chinese medicine for diabetes therapy (10). The saponin astragaloside IV has been reported to exert various pharmacological effects; astragaloside IV inhibited hepatic glycogen phosphorylase (GP) and glucose-6-phosphatase (G6P) activities thereby decreasing serum glucose levels in diabetic mice (12), attenuated lipolysis and reduced insulin resistance induced by tumor necrosis 
factor $\alpha(\mathrm{TNF} \alpha)$ in 3T3-L1 adipocytes (13), improved the symptoms of metabolic syndrome in fructose-fed rats (14), prevented human cardiovascular pathological changes and protected against cardiovascular injury in rats (15-18) improved renal function (19-22), reduced the progression of peripheral neuropathy (23), and attenuated inflammatory responses by suppressing the nuclear factor- $\kappa \mathrm{B}(\mathrm{NF}-\kappa \mathrm{B})$ pathway (24-26). $\mathrm{Xu}$ et al (27) reported that other astragalosides, astragaloside II and isoastragaloside I, elevated serum levels of adiponectin and alleviated insulin resistance and glucose intolerance in obese mice. Our research team has previously found that astragaloside IV decreases serum FFA and glucose levels in mice fed a high-fat diet, and improves insulin sensitivity (13). In order to examine the mechanisms through which astragaloside IV decreases serum glucose concentrations, we selected the major organ responsible for glucose clearance, skeletal muscle, for in vitro study. Thus, we found that astragaloside IV increases basal and insulin-stimulated glucose uptake in C2C12 myotubes through the IRS1/AKT pathway and suppresses the palmitate-induced activation of the inhibitory $\kappa \mathrm{B}$ kinase $(\mathrm{IKK}) /$ inhibitor $-\kappa \mathrm{B} \alpha(\mathrm{I} \kappa \mathrm{B} \alpha)$ pathway.

\section{Materials and methods}

Materials. Astragaloside IV, palmitate and protease inhibitor cocktail were purchased from Sigma (St. Louis, MO, USA). Dulbecco's modified Eagle's medium (DMEM) and horse serum were purchased from Gibco Life Technologies (Grand Island, NY, USA). Fetal bovine serum (FBS) was obtained from PAA Laboratories, Pasching, Austria). Fatty acid-free bovine serum albumin (BSA) was purchased from Calbiochem (San Diego, CA, USA). Horseradish peroxidase-conjugated goat anti-rabbit and rabbit anti-mouse $\mathrm{IgG}$ were purchased from Cell Signaling Technology, Inc. (Beverly, MA, USA). Phosphorylated (p)-IRS1 [tyrosine (Y)612] was purchased from Santa Cruz Biotechnology, Inc. (Santa Cruz, CA, USA). An antibody against GAPDH was obtained from Novus Biologicals (Littleton, CO, USA). Antibodies against p-AKT [serine (Ser)473 and threonine (Thr)308], AKT, p-insulin receptor $\beta$ (IR $\beta$ ), glucose transporter 4 (GLUT4), $\mathrm{p}-\mathrm{IKK} \alpha / \mathrm{IKK} \beta$ and I $\kappa \mathrm{B} \alpha$ were purchased from Cell Signaling Technology, Inc. 2-Deoxy-D-[1,2-- $\left.{ }^{3} \mathrm{H}(\mathrm{N})\right]$-glucose (radiolabeled 2-DG) was purchased from Amersham (Buckinghamshire, UK), and purified human insulin was obtained from Eli Lilly (Indianapolis, IN, USA). SYBR ${ }^{\circledR}$ Premix Ex Taq ${ }^{\mathrm{TM}}$ was purchased from Takara Bio, Dalian, China). SuperScript III was purchased from Invitrogen (Carlsbad, CA, USA).

Cell culture. The mouse myoblast cell line $\mathrm{C} 2 \mathrm{C} 12$ was obtained from the American Type Culture Collection (ATCC; Manassas, VA, USA) and maintained in DMEM supplemented with $10 \%$ FBS. When the cells reached $70 \%$ confluence, the medium was replaced with differentiation medium containing DMEM and $2 \%$ horse serum, which was replaced every other day. After 4 days, the differentiated $\mathrm{C} 2 \mathrm{C} 12$ cells had fused into myotubes. Lipid-containing media were prepared by the conjugation of FFA with FFA-free BSA, according to a method previously described by Itani et al (6) with some modifications. Briefly, palmitate was dissolved in $0.1 \mathrm{~N} \mathrm{NaOH}$ and diluted in DMEM containing $2 \%$ (wt/vol) fatty acid-free BSA. The myotubes were incubated for $16 \mathrm{~h}$ in serum-free DMEM containing 2\% BSA in either the presence or absence of palmitate. The cells were then incubated with $100 \mathrm{nM}$ insulin for $30 \mathrm{~min}$. Following incubation, RNA and total proteins were extracted from the myotubes as described below. Astragaloside IV was added $2 \mathrm{~h}$ prior to palmitate exposure.

2-DG transport assay. Glucose uptake into the $\mathrm{C} 2 \mathrm{C} 12$ myotubes was measured using radiolabeled 2-DG, according to a method previously described by Perrini et al (28) with some modifications. Prior to performing the glucose transport assays, the cells were washed twice with HEPES-buffered saline (HBS). The glucose transport assays were performed by incubating the cells with HBS containing radiolabeled $2-\mathrm{DG}(0.5 \mu \mathrm{Ci} / \mathrm{ml})$ at room temperature. The cells with prior exposure to insulin (see below) were incubated in glucose uptake assay medium supplemented with insulin. After $30 \mathrm{~min}, 2-\mathrm{DG}$ uptake was terminated by three rapid washes with ice-cold phosphate-buffered saline $(\mathrm{PBS})+$ glucose. The cells were lysed in $0.1 \mathrm{~N} \mathrm{NaOH}$, and then ${ }^{3} \mathrm{H}$ was counted using a liquid scintillation spectrophotometer (Beckman Instruments, Fullerton, CA, USA).

Measurement of $m R N A$ levels. Total RNA was isolated using TRIzol reagent. The total RNA isolated by this method is undegraded and free of protein and DNA contamination. In order to perform amplification, the following sense and antisense primer sequences were used for amplification: GLUT4, 5'-GTGACTGG AACACTGGTCCTA-3' and 5'-CCAGCCACGTTGCATTG TAG-3'; Toll-like receptor 4 (TLR4), 5'-TCTTCTCCTGCCTG ACACCA-3' and 5'-TCTTCTCCTGCCTGACACCA-3'; monocyte chemotactic protein 1 (MCP-1), 5'-GGCCTGTTGTTCA C AGTTGC-3' and 5'-AGCCGACTCATTGGGATCAT-3'; tumor necrosisfactor(TNF) $\alpha, 5^{\prime}$-CACAAGATGCTGGGACAGTGA-3' and 5'-TCCTTGATGGTGGTGCATGA-3'; and interleukin-6 (IL-6), 5'-CAGCCACTGCCTTCCCTACT-3' and 5'-CAGTGCATCAT CGCTGTTCAT-3'. Preliminary experiments were performed with various amounts of cDNA to determine the non-saturating conditions of PCR amplification for all the genes studied. Therefore, under these conditions, the relative quantification of mRNA was assessed by the RT-PCR method used in this study. The expression of specific mRNAs are presented relative to the expression of the control gene [adenine phosphoribosyltransferase (APRT), 5'-CGGCAAGATCGACT ACATCG-3' and 5'-CCAGCTCAGCCTTCCCATAC-3'].

Subcellular fractionation. The subcellular fractionation of the C2C12 cells was performed as described by Tortorella and Pilch (29) with some modifications. The C2C12 cells were washed three times in ice-cold PBS, pH 7.4 (in mM: $137 \mathrm{NaCl}, 2.7 \mathrm{KCl}, 10 \mathrm{Na}_{2} \mathrm{HPO}_{4}$ and $1.8 \mathrm{KH}_{2} \mathrm{PO}_{4}$ ) and then the cells were sheared through a 22-gauge needle 15 times in HES buffer $[255 \mathrm{mM}$ sucrose, $4 \mathrm{mM}$ disodium EDTA, $20 \mathrm{mM}$ HEPES $\mathrm{pH} 7.4,10 \mu \mathrm{M}$ leupeptin, $1 \mu \mathrm{M}$ pepstatin, $1 \mu \mathrm{M}$ aprotinin, $1 \mathrm{mM}$ phenylmethylsulfonyl fluoride (PMSF) and $5 \mathrm{mM}$ benzamidine]. The homogenate was centrifuged at $19,000 \mathrm{x} \mathrm{g}$ for $20 \mathrm{~min}$. The pellet was saved and fractionated further in order to extract the following fractions: crude 'plasma membrane' (PM) fraction (P1) and crude nuclear $(\mathrm{N})$ /endoplasmic reticulum (ER) fraction. In order to obtain the PM fraction, the pellet was resuspended in HES, 
layered onto a 1.12 $\mathrm{M}$ sucrose cushion in $20 \mathrm{mM}$ HEPES and $1 \mathrm{mM}$ disodium EDTA, and centrifuged at 100,000 x g for $1 \mathrm{~h}$. The sucrose cushion interface was collected and pelleted at $40,000 \mathrm{x}$ g for $20 \mathrm{~min}$. This PM-containing pellet (P1) was resuspended in PBS plus protease inhibitors. All centrifugations were performed at $4^{\circ} \mathrm{C}$ by a Beckman Ultraspeed centrifuge (Beckman Coulter, Brea, CA, USA). GLUT4 was detected by western blot analysis as described below.

Western blot analysis. The $\mathrm{C} 2 \mathrm{C} 12$ cells grown on six-well plates were washed with ice-cold PBS and then scraped into homogenizing buffer containing $50 \mathrm{mM}$ HEPES, $\mathrm{pH} 7.4,150 \mathrm{mM} \mathrm{NaCl}, 10 \%$ glycerol, $1 \%$ Triton $\mathrm{X}-100$, $1.5 \mathrm{mM} \mathrm{MgCl} 2,1 \mathrm{mM}$ EDTA, $10 \mathrm{mM} \mathrm{Na} \mathrm{PO}_{4}, 100 \mathrm{mM} \mathrm{NaF}$, $2 \mathrm{mM} \mathrm{Na} \mathrm{VO}_{4}, 10 \mu \mathrm{g} / \mathrm{ml}$ leupeptin, $10 \mu \mathrm{g} / \mathrm{ml}$ aprotinin, and $1 \mathrm{mM}$ PMSF. The lysates were centrifuged at 13,000 rpm for $30 \mathrm{~min}$. Soluble proteins were quantitated using the bicinchoninic acid kit (Pierce Chemical Co., Rockford, IL, USA) with BSA as the standard and adjusted to $2 \mu \mathrm{g} / \mu \mathrm{l}$. Aliquots of homogenate were solubilized in Laemmli sample buffer and the protein was subjected to SDS-PAGE. Proteins were transferred to nitrocellulose membranes (Whatman; GE Healthcare, Piscataway, NJ, USA). The membranes were blocked in a solution of Tris-buffered saline containing $5 \%$ nonfat dry milk. Protein was visualized using the SuperSignal ${ }^{\circledR}$ West Pico chemiluminescent substrate (Pierce Chemical Co.) assay.

Statistical analysis. Data are presented as the means \pm SEM. The significance between groups was determined using either an unpaired two-tailed Student's t-test or one-way ANOVA as appropriate. A P-value $<0.05$ was considered to indicate a statistically significant difference.

\section{Results}

Astragaloside IV increases basal and insulin-stimulated glucose uptake in C2C12 myotubes. In order to examine the effect of astragaloside IV on glucose uptake in $\mathrm{C} 2 \mathrm{C} 12$ myotubes in the presence or absence of insulin, differentiated $\mathrm{C} 2 \mathrm{C} 12$ myotubes were serum starved overnight in $0.2 \% \mathrm{BSA}+\mathrm{DMEM}$, and were then treated with astragaloside IV at concentrations ranging from $6.25 \mu \mathrm{M}$ to $50 \mu \mathrm{M}$ for $12 \mathrm{~h}$. Astragaloside IV increased glucose uptake in the C2C12 myotubes in a dose-dependent manner with the most significant increase at $12.5 \mu \mathrm{M}$ (Fig. 1A). In the basal state, glucose uptake was elevated with increasing concentrations of astragaloside IV up to $50 \mu \mathrm{M}$ (Fig. 1A); however, in the insulin-stimulated $\mathrm{C} 2 \mathrm{C} 12$ myotubes, glucose uptake was significantly increased only at a concentration of $12.5 \mu \mathrm{M}$ astragaloside IV (Fig. 1A). We then treated the $\mathrm{C} 2 \mathrm{C} 12$ myotubes with $12.5 \mu \mathrm{M}$ astragaloside IV for different periods of time. The C2C12 myotubes showed a significant increase in glucose uptake after $1 \mathrm{~h}$, and the most significant effect was observed at $2 \mathrm{~h}$, and was sustained until $12 \mathrm{~h}$ (Fig. 1B). Astragaloside IV increased glucose uptake in $\mathrm{C} 2 \mathrm{C} 12$ myotubes in a dose- and time-dependent manner.

Astragaloside IV ameliorates palmitate-induced insulin resistance in $\mathrm{C} 2 \mathrm{Cl} 2$ myotubes. In a previous in vitro experi- ment, insulin-stimulated glucose uptake was decreased in $\mathrm{C} 2 \mathrm{C} 12$ myotubes exposed to palmitate for $16 \mathrm{~h} \mathrm{(30)}$. In the present study, we determined the effect of astragaloside IV on glucose uptake reduced by palmitate in $\mathrm{C} 2 \mathrm{C} 12$ myotubes. The C2C12 myotubes were treated with $12.5 \mu \mathrm{M}$ astragaloside IV and serum starved for $2 \mathrm{~h}$ prior to incubation with $0.75 \mathrm{mM}$ palmitate for $16 \mathrm{~h}$. A $16-\mathrm{h}$ incubation period with $0.75 \mathrm{mM}$ palmitate decreased the insulin-stimulated uptake of 2-DG $(\mathrm{P}<0.05$ vs. insulin-stimulated cells incubated with BSA alone) (Fig. 1C). However, pre-treatment with astragaloside IV restored glucose uptake in the palmitate-exposed $\mathrm{C} 2 \mathrm{C} 12$ myotubes $(\mathrm{P}<0.05)$ (Fig. 1C).

Effect of astragaloside IV on the phosphorylation of IR $\beta$ in the insulin-stimulated state. The subcellular localization of IR $\beta$ was evaluated by subcellular fractionation followed by western blot analysis. As shown in Fig. 2, astragaloside IV had no significant effect on the protein expression or the phosphorylation of IR $\beta$ in the presence or absence of palmitate.

Effect of astragaloside IV on the phosphorylation of IRS1 and AKT in the basal state. The proteins, IRS1 and AKT, play important roles in insulin signaling, and the phosphorylation of IRS1 and AKT may promote glucose uptake in skeletal muscle (31). In this experiment, we found that astragaloside IV significantly enhanced the phosphorylation of IRS1(Y612) as well as AKT (Ser473) and (Thr308) (P<0.05; Fig. 3A).

Effect of astragaloside IV on the phosphorylation of IRSI and AKT in the insulin-stimulated state. As expected, astragaloside IV significantly increased the insulin-stimulated phosphorylation of IRS1(Y612) and AKT (Ser473) and (Thr308) $(\mathrm{P}<0.05$; Fig. 3B) in the $\mathrm{C} 2 \mathrm{C} 12$ myotubes. Palmitate exposure reduced the levels of total protein as well as the phosphorylation of IRS1 and AKT. Pre-treatment with astragaloside IV ameliorated the reduced phosphorylation levels; however, it had no effect on the protein expression of IRS1 and AKT ( $<<0.05$; Fig. 3B).

Effect of astragaloside IV on the mRNA and protein expression of GLUT4. The elevated mRNA and protein expression of GLUT4 is associated with increased cell surface levels of GLUT4 (32). Thus, we examined the mRNA and protein expression of GLUT4 in the $\mathrm{C} 2 \mathrm{C} 12$ myotubes in the presence or absence of palmitate. Astragaloside IV had no direct effect on the mRNA and protein expression of GLUT4 in the $\mathrm{C} 2 \mathrm{C} 12$ myotubes (Fig. 4A and B; $\mathrm{P}<0.05$ ). Exposure to palmitate for $16 \mathrm{~h}$ caused a marked reduction in the mRNA and protein levels of GLUT4 in the C2C12 myotubes; however, pretreatment with astragaloside IV attenuated the deleterious effect of palmitate (Fig. 4A and B; $\mathrm{P}<0.05$ ).

Astragaloside IV enhances the basal and insulin-stimulated translocation of GLUT4, and partly attenuates the palmitate-induced decrease in the insulin-stimulated translocation of GLUT4. The subcellular localization of GLUT4 was evaluated by subcellular fractionation followed by western blot analysis. As shown in Fig. 4C, the surface levels of basal GLUT4 were increased by astragaloside IV $(\mathrm{P}<0.05)$, whereas basal GLUT4 surface levels were not detected in the palmitate-exposed group. Insulin stimulation resulted in a 

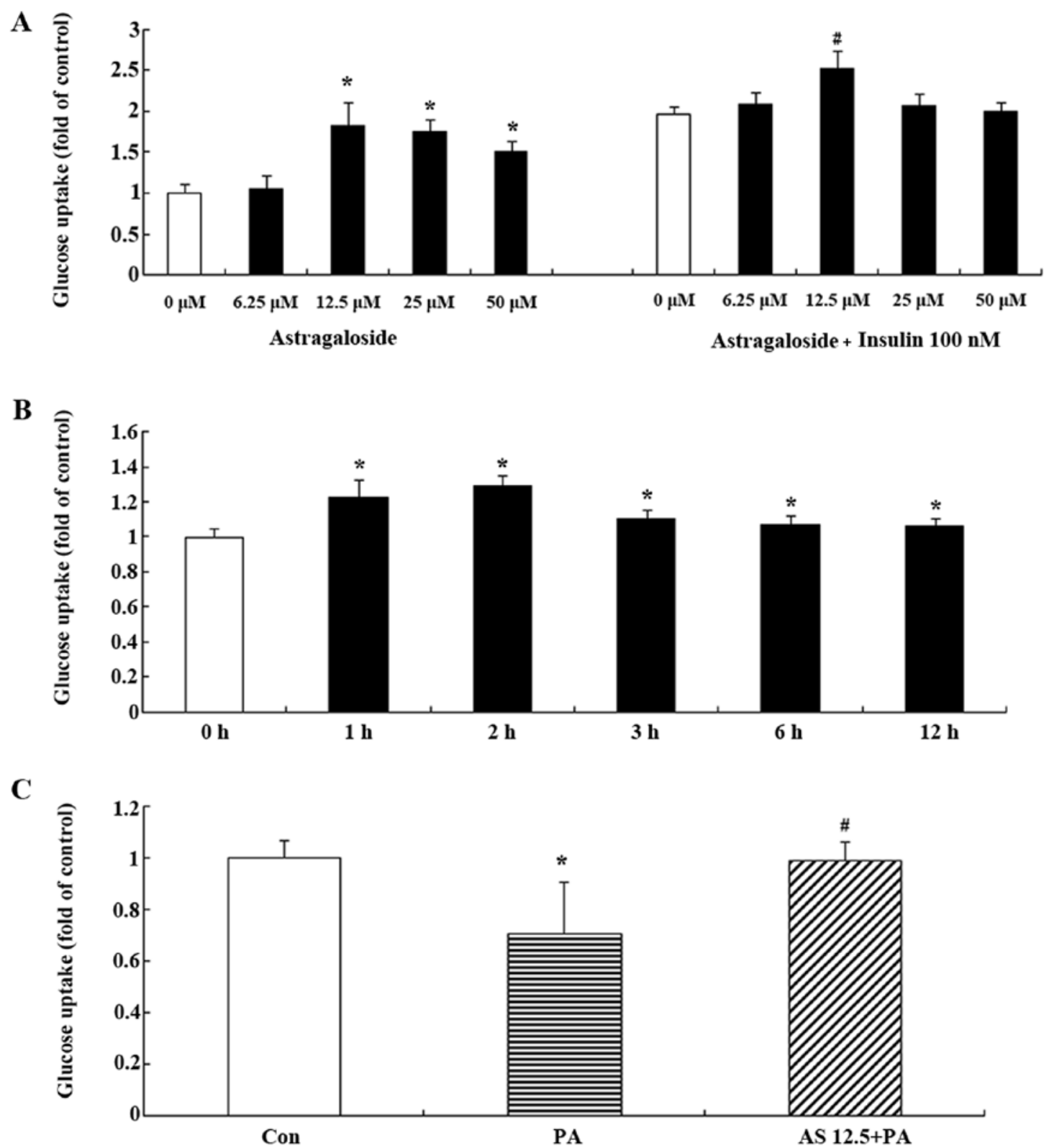

Figure 1. Dose- and time-dependent effect of astragaloside IV on radiolabeled 2-deoxyglucose (2DG) uptake in C2C12 myotubes. C2C12 myoblasts were cultured and differentiated into myotubes as described in the Materials and methods. (A) Myotubes were incubated with or without astragaloside IV at the indicated concentrations for $12 \mathrm{~h}$, in the presence or absence of insulin stimulation $(100 \mathrm{nM})$ for $30 \mathrm{~min}$. Thereafter, $\left[{ }^{3} \mathrm{H}\right] 2 \mathrm{DG}$ uptake was determined as described in the Materials and methods. (B) Myotubes were treated with $12.5 \mu \mathrm{M}$ Astragaloside IV for the indicated periods of time. Data are presented as the means \pm SEM. ${ }^{*} \mathrm{P}<0.05$ between the indicated treatment and the corresponding corresponding control. (C) Astragaloside IV ameliorated palmitate-induced insulin resistance in C2C12 myotubes. C2C12 myotubes were treated with $12.5 \mu \mathrm{M}$ astragaloside IV for $2 \mathrm{~h}$, exposed to $0.75 \mathrm{mM}$ BSA-complexed palmitate or BSA for $16 \mathrm{~h}$, and finally incubated with $100 \mathrm{nM}$ insulin for $30 \mathrm{~min} .{ }^{~} \mathrm{P}<0.05$ between the astragaloside $\mathrm{IV}+$ palmitate $(\mathrm{PA})+$ insulin group and the $\mathrm{PA}+$ insulin group. ${ }^{*} \mathrm{P}<0.05$ between the control (Con) + insulin group and the PA + insulin group. AS, astragaloside IV.

marked increase in the GLUT4 levels at the cell surface in the C2C12 myotubes (Fig. 4C). Exposure to palmitate decreased the insulin-stimulated translocation of GLUT4, and this effect was partly antagonized by astragaloside IV ( $\mathrm{P}<0.05$; Fig. 4C).

Astragaloside IV suppresses the activation of the IKK/I $\kappa B \alpha$ pathway. It is well known that the IKK/I $\mathrm{B} \alpha / \mathrm{NF}-\kappa \mathrm{B}$ pathway plays an important role in the regulation of inflammatory factors, and IKK and $\mathrm{I} \kappa \mathrm{B} \alpha$ are key proteins in this pathway. In the basal state, $\mathrm{NF}-\kappa \mathrm{B}$ binds to its inhibitor $\mathrm{I} \kappa \mathrm{B} \alpha$ to form an inactivated complex in the cytosol. Exposure to palmitate initiates the IKK/I $\mathrm{BB} \alpha / \mathrm{NF}-\kappa \mathrm{B}$ cascade, thus activating IKK, which then phosphorylates $\mathrm{I} \kappa \mathrm{B} \alpha$, causing the release of $\mathrm{I} \kappa \mathrm{B} \alpha$ from $N F-\kappa B$. NF- $\kappa$ B then translocates to the nucleus where it promotes the expression of various inflammatory factors (45). In order to determine the effect of astragaloside IV on the $\mathrm{IKK} / \mathrm{I} \kappa \mathrm{B} \alpha / \mathrm{NF}-\kappa \mathrm{B}$ cascade, we detected the levels of $\mathrm{p}-\mathrm{IKK}$ and $\mathrm{I} \kappa \mathrm{B} \alpha$ using western blot analysis. The four-day differentiated $\mathrm{C} 2 \mathrm{C} 12$ myotubes were incubated with astragaloside IV $(12.5 \mu \mathrm{M}, 2 \mathrm{~h})$ prior to stimulation with and without $0.75 \mathrm{mM}$ palmitate for $1.5 \mathrm{~h}$. As shown in Fig. $5 \mathrm{~A}$, palmitate activated IKK (as demonstrated by the increased level of p-IKK), which lead to the degradation of $\mathrm{I} \kappa \mathrm{B} \alpha$ (as demonstrated by the decreased level of I $\mathrm{B} \alpha$ ) (Fig. 5B). Pre-treatment with astragaloside IV for 

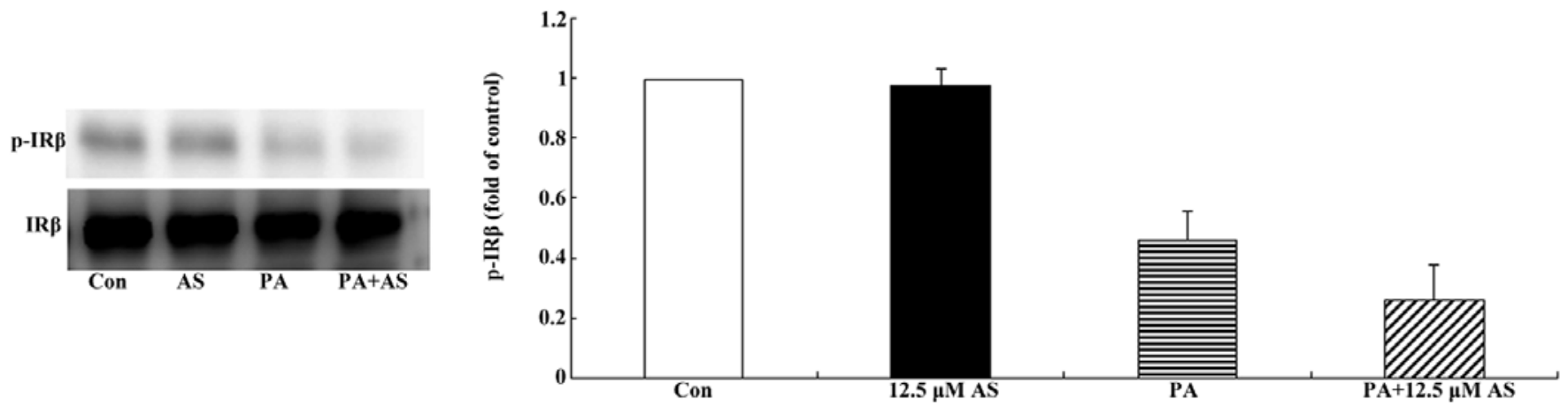

Figure 2. Effect of astragaloside IV on the phosphorylation of insulin receptor $\beta$ (IR $\beta)$ in insulin-stimulated $\mathrm{C} 2 \mathrm{C} 12$ myotubes. The $\mathrm{C} 2 \mathrm{C} 12$ myotubes were treated with astragaloside IV for $2 \mathrm{~h}$ prior to incubation with or without $0.75 \mathrm{mM}$ palmitate for $16 \mathrm{~h}$, and then incubated with $100 \mathrm{nM}$ insulin for $30 \mathrm{~min}$. Astragaloside IV had no effect on the protein expression of IR $\beta$ or the phosphorylation of IR $\beta$, which was reduced by exposure to palmitate. PA, palmitate; AS, astragaloside IV.
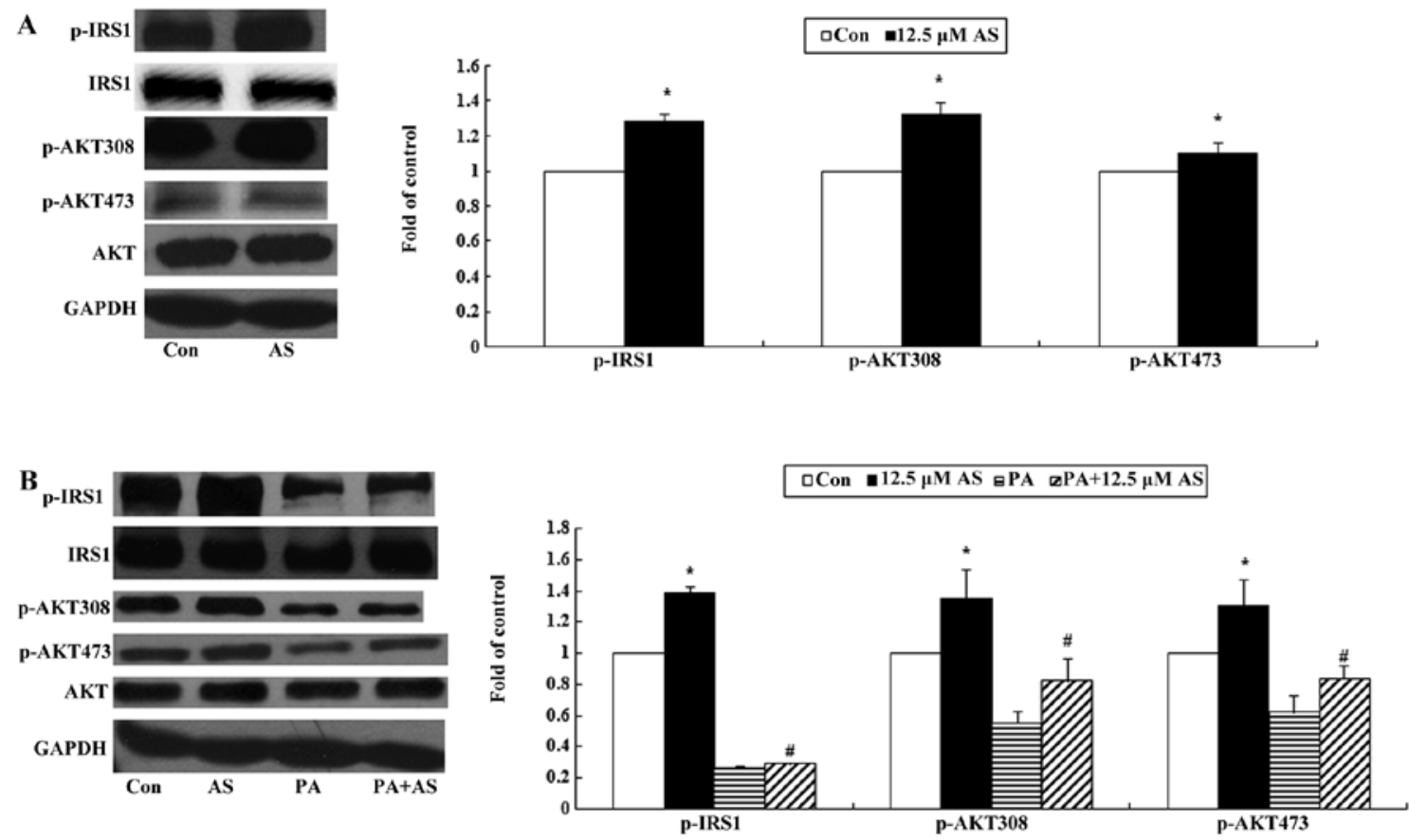

Figure 3. (A) Astragaloside IV increased the phosphorylation of insulin receptor substrate 1 (IRS1) and protein kinase B (AKT) in C2C12 myotubes in the basal state. The $\mathrm{C} 2 \mathrm{C} 12$ myotubes were treated with or without $12.5 \mu \mathrm{M}$ astragaloside IV for $2 \mathrm{~h}$. ${ }^{*} \mathrm{P}<0.05$ between the indicated treatment and the corresponding corresponding control. (B) Astragaloside IV increased the phosphorylation of IRS1 and AKT in insulin-stimulated C2C12 myotubes in the presence or absence of palmitate. The $\mathrm{C} 2 \mathrm{C} 12$ myotubes were treated with or without astragaloside IV for $2 \mathrm{~h}$ prior to incubation with or without $0.75 \mathrm{mM}$ palmitate for $16 \mathrm{~h}$, and then incubated with $100 \mathrm{nM}$ insulin for $30 \mathrm{~min}$. ${ }^{*} \mathrm{P}<0.05$ between the astragaloside IV treatment group and corresponding control; " $\mathrm{P}<0.05$ between the PA group and the PA + 12.5 $\mu \mathrm{M}$ AS group. PA, palmitate; AS, astragaloside IV; Con, control.

$2 \mathrm{~h}$ suppressed the activation of IKK and the degradation of $\mathrm{I \kappa B} \alpha$ (Fig. 5; $\mathrm{P}<0.05)$; this is indicates the inhibitory effect of astragaloside IV on the IKK/IкB $\alpha / \mathrm{NF}-\kappa \mathrm{B}$ cascade.

Astragaloside IV decreases the $m R N A$ expression of $M C P-1$, $I L-6$ and $T N F \alpha$. In vitro, the exposure of skeletal muscle cells to palmitate and subsequent incubation also induced the expression of proinflammatory factors such as IL-6 and TNFa. Following a 4-h incubation with $0.75 \mathrm{mM}$ palmitate, the $\mathrm{C} 2 \mathrm{C} 12$ myotubes displayed significantly elevated mRNA expression of MCP-1, IL-6 and TNF $\alpha$ (Fig. 6). Similar to the inhibitory effect of astragaloside IV on the IKK/IкB $\alpha / \mathrm{NF}-\kappa \mathrm{B}$ cascade, pre-treatment with astragaloside IV for $2 \mathrm{~h}$ suppressed the palmitate-induced increase in the mRNA expression of MCP-1, IL-6 and TNF $\alpha(\mathrm{P}<0.05)$ (Fig. 6).

Effect of astragaloside IV on the mRNA expression of TLR4. TLR4, a receptor of palmitate, is involved in FFA-induced insulin resistance. Through binding to TLR4, palmitate increases the expression of inflammatory factors by activating the IKK/IкB $\alpha / \mathrm{NF}-\kappa \mathrm{B}$ cascade, with subsequent feedback regulation of the mRNA expression of TLR4 (45). The C2C12 myotubes incubated with $0.75 \mathrm{mM}$ palmitate for $16 \mathrm{~h}$ exhibited markedly increased mRNA expression of TLR4 (Fig. 6). Pre-treatment with astragaloside IV downregulated the mRNA level of TLR4 induced by palmitate $(\mathrm{P}<0.05)$ (Fig. 6). 
A
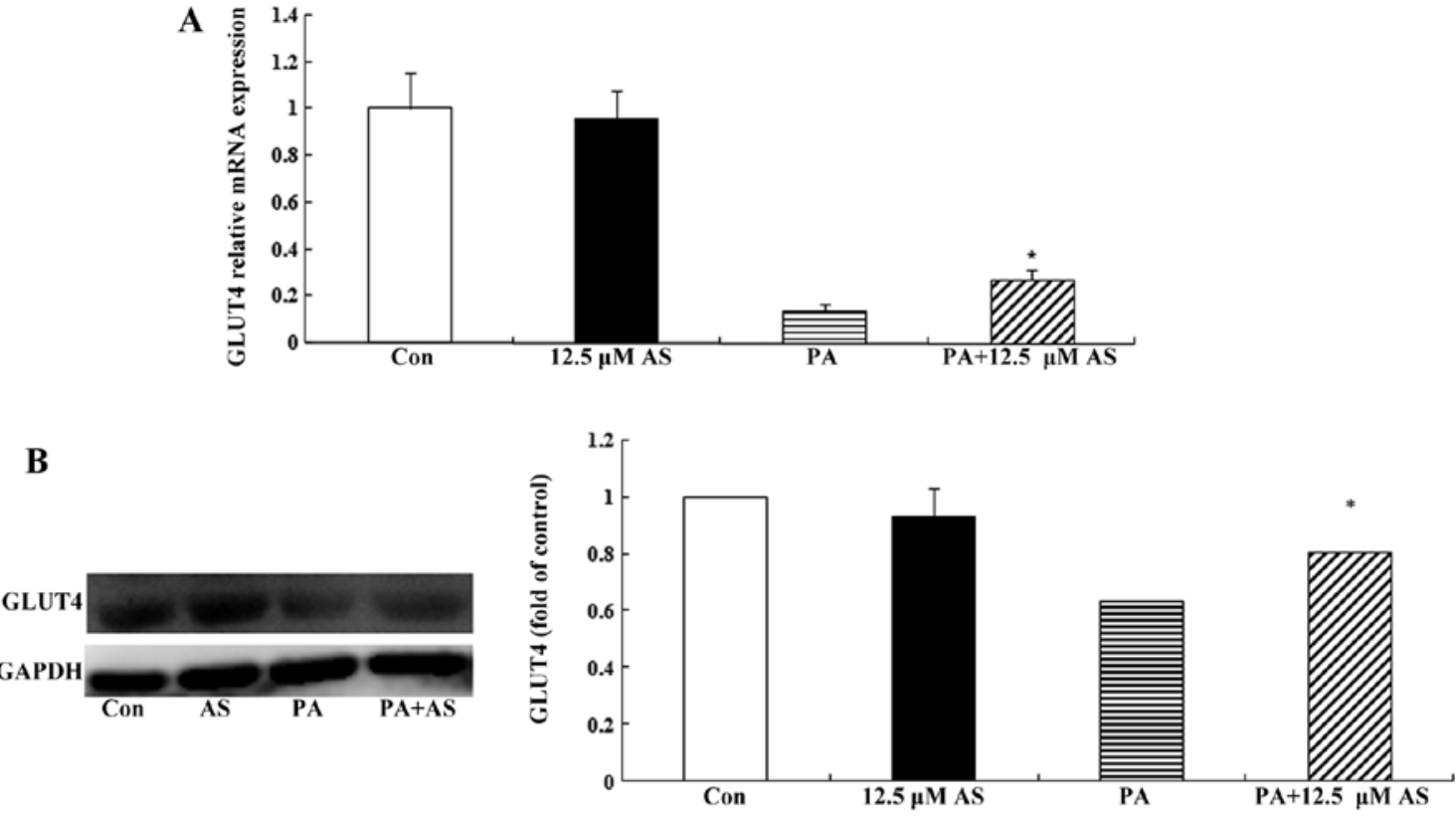

C

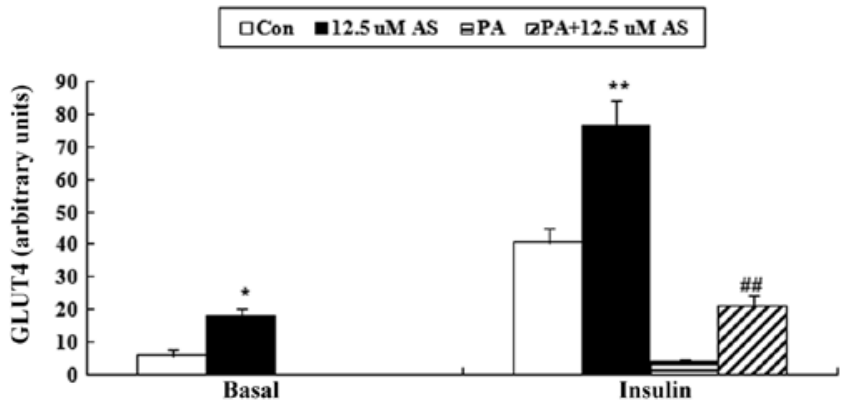

Figure 4. (A and B) Astragaloside IV attenuates the palmitate-induced decrease in the mRNA and protein levels of glucose transporter 4 (GLUT4). The C2C12 myotubes were treated with astragaloside IV for $2 \mathrm{~h}$ prior to incubation with or without $0.75 \mathrm{mM}$ palmitate for $16 \mathrm{~h}$. * $\mathrm{P}<0.05$ between the PA group and the $\mathrm{PA}+12.5 \mu \mathrm{M}$ AS group. (C) Astragaloside IV enhances the basal and insulin-stimulated translocation of GLUT4, and partly attenuates the palmitate-induced decrease in the insulin-stimulated translocation of GLUT4. The C2C12 myotubes were treated with astragaloside IV for $2 \mathrm{~h}$ prior to incubation with or without $0.75 \mathrm{mM}$ palmitate for $16 \mathrm{~h}$, and then incubated with or without $100 \mathrm{nM}$ insulin. The plasma membranes were separated as described in the Materials and methods and subsequently western blot analysis of the proteins was performed. ${ }^{* * *} \mathrm{P}<0.05$ between the astragaloside IV treatment group and corresponding control; ${ }^{\# \#} \mathrm{P}<0.05$ between the PA group and the PA $+12.5 \mu \mathrm{M}$ AS group. PA, palmitate; AS, astragaloside IV; Con, control.

\section{Discussion}

The classic pathway of insulin signaling involving the translocation of GLUT4 $(33,34)$ to the cell surface is triggered by the autophosphorylation of the insulin receptor on multiple tyrosine residues following insulin binding. This results in the tyrosine phosphorylation of a family of IRS proteins and the activation of a complex network of downstream molecules, including phosphatidylinositol 3-kinase (PI3K) and the serine/threonine kinase AKT. Skeletal muscle is the most important tissue involved in insulin-stimulated glucose disposal, and insulin resistance in skeletal muscle is a major defect in most obese phenotypes (35).

The present study demonstrated that astragaloside IV regulates glucose uptake and delineates the proximal signaling events mediating this response. We demonstrated that astragaloside IV increased basal glucose uptake in the $\mathrm{C} 2 \mathrm{C} 12$ myotubes in a dose- and time-dependent manner; the highest rate of glucose uptake was observed at a concentration of $12.5 \mu \mathrm{M}$ of astragaloside IV and a treatment period of $2 \mathrm{~h}$ produced the most significant effect on glucose uptake. Astragaloside IV also increased insulin-stimulated glucose uptake, which revealed that it is capable of enhancing insulin sensitivity in $\mathrm{C} 2 \mathrm{C} 12$ myotubes. We found that astragaloside IV increased glucose uptake in the $\mathrm{C} 2 \mathrm{C} 12$ myotubes through the phosphorylation of IRS1 and AKT in the basal state. Astragaloside IV also increased the insulin-stimulated phosphorylation of IRS1 and AKT, thereby displaying a synergistic interaction with insulin. We also examined the phosphorylation of IR $\beta$ and found that astragaloside IV did not activate IR $\beta$, which suggests that astragaloside IV activated IRS1 and AKT independently of IR $\beta$.

Randle et al (36), described the glucose fatty-acid cycle, which is a metabolic pathway linking fat and carbohydrate metabolism. In vivo, fatty acid metabolism not only provides ATP, but also decreases glucose consumption. Elevated fatty acid uptake always follows increased fatty acid oxidation, which leads to reduced glucose consumption and insulin tolerance. Abnormal fatty acid metabolism exists in obese and diabetic patients due to elevated basal lipolysis and the impaired ability of insulin to mediate the conversion of serum 
A

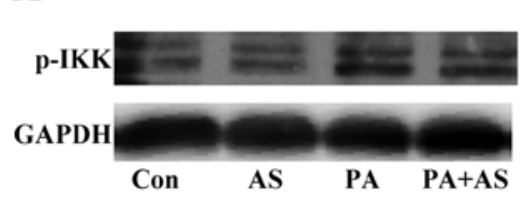

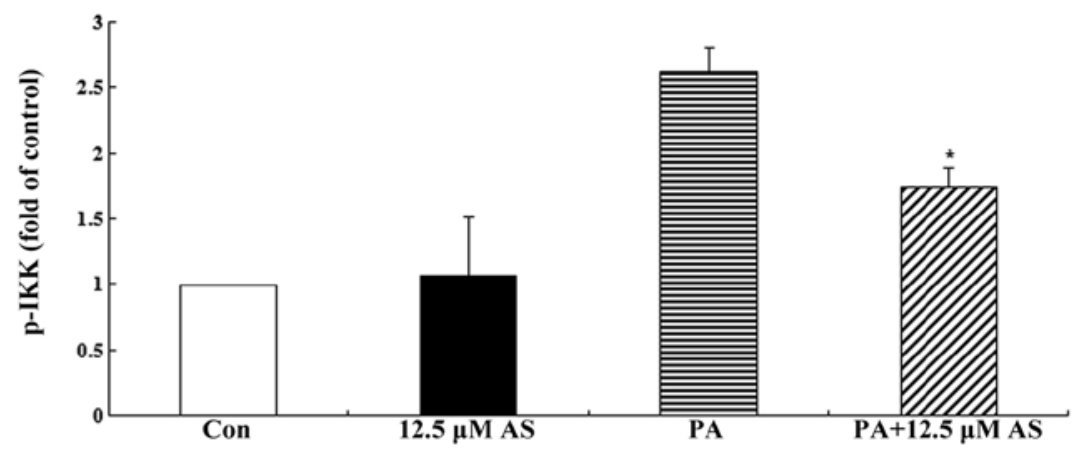

B
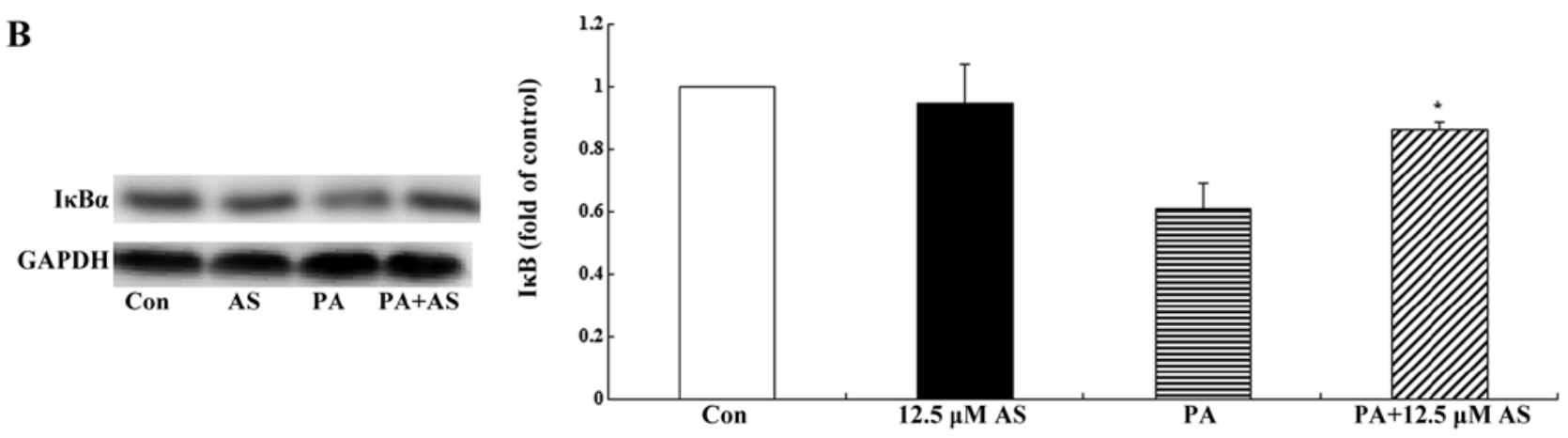

Figure 5. (A) Astragaloside IV suppresses the palmitate-induced increase in the phosphorylation of inhibitory $\kappa \mathrm{B}$ kinase (IKK). The C2C12 myotubes were treated with astragaloside IV for $2 \mathrm{~h}$ prior to incubation with or without $0.75 \mathrm{mM}$ palmitate for $1.5 \mathrm{~h}$. ${ }^{*} \mathrm{P}<0.05$ between the PA group and the PA $+12.5 \mu \mathrm{M}$ AS group. (B) Astragaloside IV inhibited the palmitate-induced degradation of $\mathrm{I} \kappa \mathrm{B} \alpha$. The $\mathrm{C} 2 \mathrm{C} 12$ myotubes were treated with astragaloside IV for $2 \mathrm{~h}$ prior to incubation with or without $0.75 \mathrm{mM}$ palmitate for $1.5 \mathrm{~h}$. ${ }^{*} \mathrm{P}<0.05$ between the PA group and the PA $+12.5 \mu \mathrm{M}$ AS group. PA, palmitate; AS, astragaloside IV; Con, control.

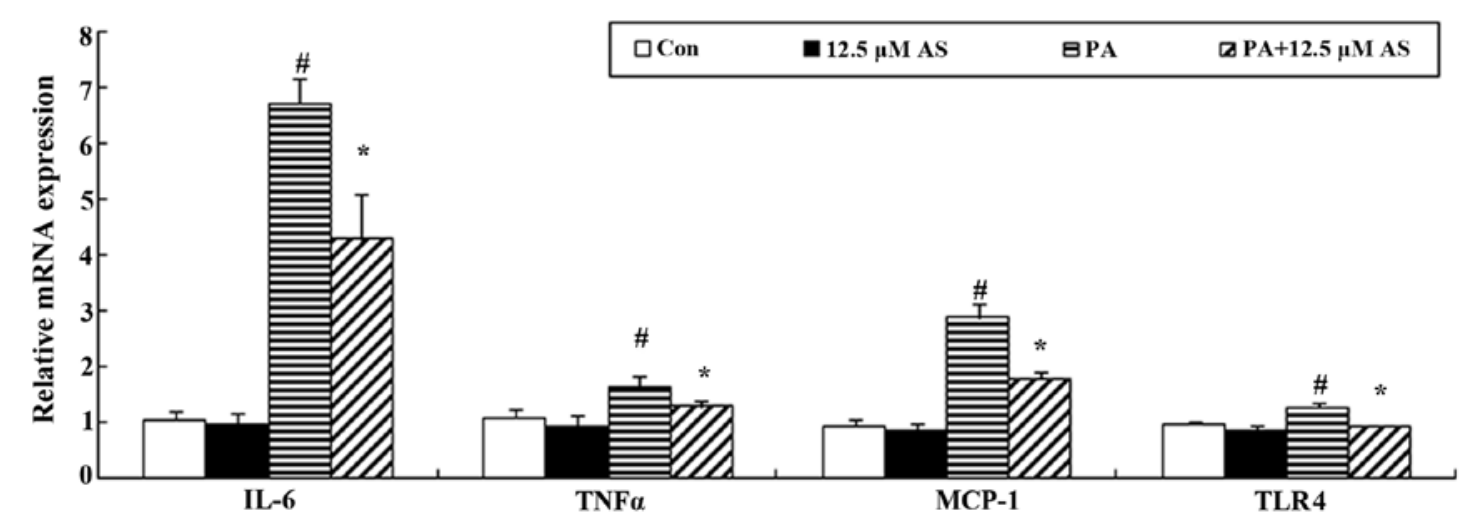

Figure 6. Astragaloside IV suppresses the palmitate-induced increase in the mRNA expression of interleukin-6 (IL-6), tumor necrosis factor $\alpha$ (TNF $\alpha$ ), monocyte chemotactic protein-1 (MCP-1) and Toll-like receptor 4 (TLR4). The C2C12 myotubes were treated with astragaloside IV for $2 \mathrm{~h}$ prior to incubation with or without $0.75 \mathrm{mM}$ palmitate for $4 \mathrm{~h}$. ${ }^{*} \mathrm{P}<0.05$ between the PA group and the $\mathrm{PA}+12.5 \mu \mathrm{M}$ AS group. ${ }^{*} \mathrm{P}<0.05$ between the control group and the palmitate group. PA, palmitate; AS, astragaloside IV; Con, control.

FFA into triglyceride (37). Insulin-stimulated glucose transport significantly decreased in skeletal muscle obtained from patients with type 2 diabetes (38) and obesity (39). The translocation of GLUT4 was reduced by $90 \%$ in the skeletal muscle of type 2 diabetic patients (40). In this study, astragaloside IV enhanced the basal and insulin-stimulated translocation of GLUT4. The C2C12 myotubes exposed to palmitate exhibited a marked decrease in the mRNA and protein expression of GLUT4 as well as a decrease in the translocation of GLUT4, whereas pre-treatment with astragaloside IV partly attenuated the deleterious effects of palmitate.
Our results indicated that palmitate inhibited the activation of IRS1 and AKT in the $\mathrm{C} 2 \mathrm{C} 12$ myotubes, reduced the insulin-stimulated translocation of GLUT4, and finally decreased glucose uptake. Pre-treatment with astragaloside IV ameliorated the palmitate-induced decrease in the phosphorylation of IRS1 and AKT, and partly attenuated the palmitate-induced decrease in the insulin-stimulated translocation of GLUT4. Astragaloside IV displayed a significant effect on insulin resistance induced by palmitate in skeletal muscle.

Previous research has demonstrated that type 2 diabetes and obesity are associated with significant increases in 
inflammatory factors (41), and macrophage infiltration in adipose tissue $(42,43)$, which demonstrates the close association between the immune system and insulin resistance (42,44-46). The IKK/I $\kappa \mathrm{B} \alpha$ pathway is closely associated with insulin resistance $(45,47)$; it links inflammation to insulin resistance. TLRs are innate immune receptors; the immune response to invading microorganisms is mediated through the activation of TLRs (48). Increasing evidence has demonstrated that saturated fatty acids activate TLR4 signaling which activates the NF- $\kappa \mathrm{B}$ pathway $(49,50)$, and play roles in insulin resistance $(47,51)$. Reyna et al (52) recognized the importance of TLR4 after examining insulin resistant skeletal muscle obtained from obese and type 2 diabetic subjects. Mice lacking TLR4 have been shown to be partially protected against fatty acid-induced insulin resistance in skeletal muscle $(49,53,54)$. The activation of the $\mathrm{IKK} / \mathrm{I} \kappa \mathrm{B} \alpha$ pathway increases the expression of IL- 6 and $\mathrm{TNF} \alpha$, which reduces insulin resistance in skeletal muscle $(48,54)$. IL- 6 may be the most critical factor involved in the modulation of insulin resistance $(55,56)$; a previous study found that the concentration of IL-6 was 2-3-fold higher in obese subjects without type 2 diabetes in comparison with lean subjects (55). However, Sell et al (57) suggested that MCP-1 was the most important among a number of cytokines, and that physiological concentrations of MCP-1 may lead to insulin resistance.

Our results confirmed that palmitate may bind to TLR4, thus activating IKK, which then phosphorylates $\mathrm{I} \kappa \mathrm{B} \alpha$, causing the release of $\mathrm{I} \kappa \mathrm{B} \alpha$ from $\mathrm{NF}-\kappa \mathrm{B}$. NF- $\kappa \mathrm{B}$ then translocates to the nucleus where it promotes the expression of inflammatory factors, such as MCP-1, IL-6 and TNF $\alpha$. These inflammatory factors inhibit the activation of insulin pathway proteins, finally decreasing insulin sensitivity. The pre-treatment of the palmitate-exposed $\mathrm{C} 2 \mathrm{C} 12$ myotubes with astragaloside IV decreased the mRNA expression of TLR4, suppressed the activation of IKK and the degradation of $\mathrm{I} \kappa \mathrm{B} \alpha$, reduced $\mathrm{NF}-\kappa \mathrm{B}$ activation (data not shown), and thus reduced the mRNA expression of MCP-1, IL- 6 and TNF $\alpha$, consequently reducing the insulin resistance induced by palmitate. These findings are limited by the absence of data regarding NF- $\kappa \mathrm{B}$ due to a lack of funding and we plan to investigate this aspect further in the future.

In conclusion, astragaloside IV increased glucose uptake in $\mathrm{C} 2 \mathrm{C} 12$ myotubes through the IRS1/AKT pathway. Moreover, astragaloside IV suppressed the the palmitate-induced activation of the IKK/I $\mathrm{B}$ B $\alpha$ pathway and reduced the secretion of inflammatory factors. These results may explain, at least in part, the antidiabetic and insulin-sensitizing effects of astragaloside IV and A. membranaceus.

\section{References}

1. DeFronzo RA, Gunnarsson R, Björkman O, Olsson M and Wahren J: Effects of insulin on peripheral and splanchnic glucose metabolism in noninsulin-dependent (type II) diabetes mellitus. J Clin Invest 76: 149-155, 1985.

2. Kiens B, Roemen TH and van der Vusse GJ: Muscular long-chain fatty acid content during graded exercise in humans. Am J Physiol 276: E352-E357, 1999.

3. Pirola L, Bonnafous S, Johnston AM, Chaussade C, Portis F and Van Obberghen E: Phosphoinositide 3-kinase-mediated reduction of Insulin receptor substrate-1/2 protein expression via different mechanisms contributes to the insulin-induced desensitization of its signaling pathways in L6 muscle cells. J Biol Chem 278: 15641-15651, 2003.

4. Boden G: Fatty acid-induced inflammation and insulin resistance in skeletal muscle and liver. Curr Diab Rep 6: 177-181, 2006.
5. Abdul-Ghani MA, Muller FL, Liu Y, Chavez AO, Balas B, Zuo P, Chang Z, Tripathy D, Jani R, Molina-Carrion M, et al: Deleterious action of FA metabolites on ATP synthesis: possible link between lipotoxicity, mitochondrial dysfunction, and insulin resistance. Am J Physiol Endocrinol Metab 295: E678-E685, 2008.

6. Itani SI, Zhou Q, Pories WJ, MacDonald KG and Dohm GL: Involvement of protein kinase $\mathrm{C}$ in human skeletal muscle insulin resistance and obesity. Diabetes 49: 1353-1358, 2000.

7. Koistinen HA, Galuska D, Chibalin AV, Yang J, Zierath JR, Holman GD and Wallberg-Henriksson H: 5-amino-imidazole carboxamide riboside increases glucose transport and cell-surface GLUT4 content in skeletal muscle from subjects with type 2 diabetes. Diabetes 52: 1066-1072, 2003.

8. Wu W, Tang S, Shi J, Yin W, Cao S, Bu R, Zhu D and Bi Y: Metformin attenuates palmitic acid-induced insulin resistance in L6 cells through the AMP-activated protein kinase/sterol regulatory element-binding protein-1c pathway. Int J Mol Med 35: 1734-1740, 2015.

9. Karlsson HK, Hällsten K, Björnholm M, Tsuchida H, Chibalin AV, Virtanen KA, Heinonen OJ, Lönnqvist F, Nuutila P and Zierath JR: Effects of metformin and rosiglitazone treatment on insulin signaling and glucose uptake in patients with newly diagnosed type 2 diabetes: a randomized controlled study. Diabetes 54: 1459-1467, 2005.

10. Meshkani R, Sadeghi A, Taheripak G, Zarghooni M, Gerayesh-Nejad S and Bakhtiyari S: Rosiglitazone, a PPAR $\gamma$ agonist, ameliorates palmitate-induced insulin resistance and apoptosis in skeletal muscle cells. Cell Biochem Funct 32: 683-691, 2014

11. Steinberg GR, Watt MJ, Ernst M, Birnbaum MJ, Kemp BE and Jørgensen SB: Ciliary neurotrophic factor stimulates muscle glucose uptake by a PI3-kinase-dependent pathway that is impaired with obesity. Diabetes 58: 829-839, 2009.

12. Lv L, Wu SY, Wang GF, Zhang JJ, Pang JX, Liu ZQ, Xu W, Wu SG and Rao JJ: Effect of astragaloside IV on hepatic glucose-regulating enzymes in diabetic mice induced by a high-fat diet and streptozotocin. Phytother Res 24: 219-224, 2010.

13. Jiang B, Yang Y, Jin H, Shang W, Zhou L, Qian L and Chen M: Astragaloside IV attenuates lipolysis and improves insulin resistance induced by TNFalpha in 3T3-L1 adipocytes. Phytother Res 22: 1434-1439, 2008.

14. Zhang N, Wang XH, Mao SL and Zhao F: Astragaloside IV improves metabolic syndrome and endothelium dysfunction in fructose-fed rats. Molecules 16: 3896-3907, 2011.

15. Li HB, Ge YK, Zhang L and Zheng XX: Astragaloside IV improved barrier dysfunction induced by acute high glucose in human umbilical vein endothelial cells. Life Sci 79: 1186-1193, 2006.

16. Li ZP and Cao Q: Effects of astragaloside IV on myocardial calcium transport and cardiac function in ischemic rats. Acta Pharmacol Sin 23: 898-904, 2002.

17. Zhang S, Tang F, Yang Y, Lu M, Luan A, Zhang J, Yang J and Wang H: Astragaloside IV protects against isoproterenol-induced cardiac hypertrophy by regulating NF- $\kappa \mathrm{B} / \mathrm{PGC}-1 \alpha$ signaling mediated energy biosynthesis. PLoS One 10: e0118759, 2015.

18. Lu M, Tang F, Zhang J, Luan A, Mei M, Xu C, Zhang S, Wang H and Maslov LN: Astragaloside IV attenuates injury caused by myocardial ischemia/reperfusion in rats via regulation of Toll-like receptor 4/nuclear factor- $\kappa \mathrm{B}$ signaling pathway. Phytother Res 29: 599-606, 2015.

19. Chen J, Gui D, Chen Y, Mou L, Liu Y and Huang J: Astragaloside IV improves high glucose-induced podocyte adhesion dysfunction via alpha3betal integrin upregulation and integrin-linked kinase inhibition. Biochem Pharmacol 76: 796-804, 2008.

20. Ai P, Yong G, Dingkun G, Qiuyu Z, Kaiyuan Z and Shanyan L: Aqueous extract of Astragali Radix induces human natriuresis through enhancement of renal response to atrial natriuretic peptide. J Ethnopharmacol 116: 413-421, 2008.

21. Wang ZS, Xiong F, Xie XH, Chen D, Pan JH and Cheng L: Astragaloside IV attenuates proteinuria in streptozotocin-induced diabetic nephropathy via the inhibition of endoplasmic reticulum stress. BMC Nephrol 16: 44, 2015.

22. Lu WS, Li S, Guo WW, Chen LL and Li YS: Effects of Astragaloside IV on diabetic nephropathy in rats. Genet Mol Res 14: 5427-5434, 2015.

23. Yu J, Zhang Y, Sun S, Shen J, Qiu J, Yin X, Yin H and Jiang S: Inhibitory effects of astragaloside IV on diabetic peripheral neuropathy in rats. Can J Physiol Pharmacol 84: 579-587, 2006.

24. Zhang WJ, Hufnagl P, Binder BR and Wojta J: Antiinflammatory activity of Astragaloside IV is mediated by inhibition of NF-kappaB activation and adhesion molecule expression. Thromb Haemost 90: 904-914, 2003. 
25. Zhao P, Wang Y, Zeng S, Lu J, Jiang TM and Li YM: Protective effect of astragaloside IV on lipopolysaccharide-induced cardiac dysfunction via downregulation of inflammatory signaling in mice. Immunopharmacol Immunotoxicol 37: 428-433, 2015.

26. Zhang WJ and Frei B: Astragaloside IV inhibits NF-kB activation and inflammatory gene expression in LPS-treated mice. Mediators Inflamm 2015: 274314, 2015.

27. Xu A, Wang H, Hoo RL, Sweeney G, Vanhoutte PM, Wang Y, Wu D, Chu W, Qin G and Lam KS: Selective elevation of adiponectin production by the natural compounds derived from a medicinal herb alleviates insulin resistance and glucose intolerance in obese mice. Endocrinology 150: 625-633, 2009.

28. Perrini S, Natalicchio A, Laviola L, Belsanti G, Montrone C, Cignarelli A, Minielli V, Grano M, De Pergola G, Giorgino R and Giorgino F: Dehydroepiandrosterone stimulates glucose uptake in human and murine adipocytes by inducing GLUT1 and GLUT4 translocation to the plasma membrane. Diabetes 53: 41-52, 2004.

29. Tortorella LL and Pilch PF: C2C12 myocytes lack an insulin-responsive vesicular compartment despite dexamethasone-induced GLUT4 expression. Am J Physiol Endocrinol Metab 283: E514-E524, 2002.

30. Jové M, Planavila A, Sánchez RM, Merlos M, Laguna JC and Vázquez-Carrera M: Palmitate induces tumor necrosis factor-alpha expression in $\mathrm{C} 2 \mathrm{C} 12$ skeletal muscle cells by a mechanism involving protein kinase $\mathrm{C}$ and nuclear factor-kappaB activation. Endocrinology 147: 552-561, 2006.

31. Griffin ME, Marcucci MJ, Cline GW, Bell K, Barucci N, Lee D, Goodyear LJ, Kraegen EW, White MF and Shulman GI: Free fatty acid-induced insulin resistance is associated with activation of protein kinase $\mathrm{C}$ theta and alterations in the insulin signaling cascade. Diabetes 48: 1270-1274, 1999.

32. Tabandeh MR, Jafari H, Hosseini SA and Hashemitabar M Ginsenoside $\mathrm{Rb} 1$ stimulates adiponectin signaling in $\mathrm{C} 2 \mathrm{C} 12$ muscle cells through up-regulation of AdipoR1 and AdipoR2 proteins. Pharm Biol 53: 125-132, 2015.

33. Bryant NJ, Govers R and James DE: Regulated transport of the glucose transporter GLUT4. Nat Rev Mol Cell Biol 3: 267-277, 2002.

34. O'Gorman DJ, Karlsson HK, McQuaid S, Yousif O, Rahman Y, Gasparro D, Glund S, Chibalin AV, Zierath JR and Nolan JJ: Exercise training increases insulin-stimulated glucose disposal and GLUT4 (SLC2A4) protein content in patients with type 2 diabetes. Diabetologia 49: 2983-2992, 2006.

35. Leonard BL, Watson RN, Loomes KM, Phillips AR, and Cooper GJ: Insulin resistance in the Zucker diabetic fatty rat: a metabolic characterisation of obese and lean phenotypes. Acta Diabetol 42: 162-170, 2005.

36. Randle PJ, Garland PB, Hales CN and Newsholme EA: The glucose fatty-acid cycle. Its role in insulin sensitivity and the metabolic disturbances of diabetes mellitus. Lancet 1: 785-789, 1963.

37. McGarry JD: Banting lecture 2001: dysregulation of fatty acid metabolism in the etiology of type 2 diabetes. Diabetes 51: 7-18, 2002.

38. Krook A, Björnholm M, Galuska D, Jiang XJ, Fahlman R, Myers MG Jr, Wallberg-Henriksson $\mathrm{H}$ and Zierath JR: Characterization of signal transduction and glucose transport in skeletal muscle from type 2 diabetic patients. Diabetes 49: 284-292, 2000

39. Dohm GL, Tapscott EB, Pories WJ, Dabbs DJ, Flickinger EG, Meelheim D, Fushiki T, Atkinson SM, Elton CW and Caro JF: An in vitro human muscle preparation suitable for metabolic studies. Decreased insulin stimulation of glucose transport in muscle from morbidly obese and diabetic subjects. J Clin Invest 82: 486-494, 1988

40. Ryder JW, Yang J, Galuska D, Rincón J, Björnholm M, Krook A, Lund S, Pedersen O, Wallberg-Henriksson H, Zierath JR and Holman GD: Use of a novel impermeable biotinylated photolabeling reagent to assess insulin- and hypoxia-stimulated cell surface GLUT4 content in skeletal muscle from type 2 diabetic patients. Diabetes 49: 647-654, 2000.
41. Festa A, D'Agostino R Jr, Tracy RP and Haffner SM; Insulin Resistance Atherosclerosis Study: Elevated levels of acute-phase proteins and plasminogen activator inhibitor-1 predict the development of type 2 diabetes: the insulin resistance atherosclerosis study. Diabetes 51: 1131-1137, 2002.

42. Weisberg SP, McCann D, Desai M, Rosenbaum M, Leibel RL and Ferrante AW Jr: Obesity is associated with macrophage accumulation in adipose tissue. J Clin Invest 112: 1796-1808, 2003.

43. Xu H, Barnes GT, Yang Q, Tan G, Yang D, Chou CJ, Sole J, Nichols A, Ross JS, Tartaglia LA and Chen H: Chronic inflammation in fat plays a crucial role in the development of obesity-related insulin resistance. J Clin Invest 112: 1821-1830, 2003.

44. Kanda H, Tateya S, Tamori Y, Kotani K, Hiasa K, Kitazawa R, Kitazawa S, Miyachi H, Maeda S, Egashira K and Kasuga M $\mathrm{MCP}-1$ contributes to macrophage infiltration into adipose tissue, insulin resistance, and hepatic steatosis in obesity. J Clin Invest 116: 1494-1505, 2006.

45. Sinha S, Perdomo G, Brown NF and O'Doherty RM: Fatty acid-induced insulin resistance in L6 myotubes is prevented by inhibition of activation and nuclear localization of nuclear factor kappa B. J Biol Chem 279: 41294-41301, 2004.

46. Wada $\mathrm{J}$ and Makino $\mathrm{H}$ : Innate immunity in diabetes and diabetic nephropathy. Nat Rev Nephrol 12: 13-26, 2015.

47. Yuan M, Konstantopoulos N, Lee J, Hansen L, Li ZW, Karin M and Shoelson SE: Reversal of obesity- and diet-induced insulin resistance with salicylates or targeted disruption of Ikkbeta. Science 293: 1673-1677, 2001.

48. Medzhitov R: Toll-like receptors and innate immunity. Nat Rev Immunol 1: 135-145, 2001.

49. Shi H, Kokoeva MV, Inouye K, Tzameli I, Yin H and Flier JS: TLR4 links innate immunity and fatty acid-induced insulin resistance. J Clin Invest 116: 3015-3025, 2006.

50. Hwang D: Modulation of the expression of cyclooxygenase-2 by fatty acids mediated through toll-like receptor 4-derived signaling pathways. FASEB J 15: 2556-2564, 2001.

51. Sriwijitkamol A, Christ-Roberts C, Berria R, Eagan P, Pratipanawatr T, DeFronzo RA, Mandarino LJ and Musi N: Reduced skeletal muscle inhibitor of kappaB beta content is associated with insulin resistance in subjects with type 2 diabetes: Reversal by exercise training. Diabetes 55: 760-767, 2006.

52. Reyna SM, Ghosh S, Tantiwong P, Meka CS, Eagan P, Jenkinson CP, Cersosimo E, Defronzo RA, Coletta DK, Sriwijitkamol A and Musi N: Elevated toll-like receptor 4 expression and signaling in muscle from insulin-resistant subjects. Diabetes 57: 2595-2602, 2008

53. Radin MS, Sinha S, Bhatt BA, Dedousis N and O'Doherty RM: Inhibition or deletion of the lipopolysaccharide receptor Toll-like receptor-4 confers partial protection against lipid-induced insulin resistance in rodent skeletal muscle. Diabetologia 51: 336-346, 2008

54. Tsukumo DM, Carvalho-Filho MA, Carvalheira JB, Prada PO, Hirabara SM, Schenka AA, Araújo EP, Vassallo J, Curi R, Velloso LA and Saad MJ: Loss-of-function mutation in Toll-like receptor 4 prevents diet-induced obesity and insulin resistance. Diabetes 56: 1986-1998, 2007.

55. Kern PA, Ranganathan S, Li C, Wood L and Ranganathan G: Adipose tissue tumor necrosis factor and interleukin- 6 expression in human obesity and insulin resistance. Am J Physiol Endocrinol Metab 280: E745-E751, 2001.

56. Pickup JC, Mattock MB, Chusney GD and Burt D: NIDDM as a disease of the innate immune system: association of acute-phase reactants and interleukin- 6 with metabolic syndrome $\mathrm{X}$. Diabetologia 40: 1286-1292, 1997.

57. Sell H, Dietze-Schroeder D, Kaiser U and Eckel J: Monocyte chemotactic protein-1 is a potential player in the negative cross-talk between adipose tissue and skeletal muscle. Endocrinology 147: 2458-2467, 2006. 